\title{
Polymorphisms of two Y chromosome microsatellites in Chinese cattle
}

\author{
Xin $\mathrm{CAI}^{\mathrm{a}}$, Hong CHEN ${ }^{\mathrm{ab} *}$, Shan $\mathrm{WANG}^{\mathrm{a}}$, Kai XUE ${ }^{\mathrm{a}}$, Chuzhao LEI ${ }^{\mathrm{a}}$ \\ ${ }^{a}$ College of Animal Science and Technology, Northwest A\&F University, Shaanxi Key \\ Laboratory of Agricultural Molecular Biology, Yangling, Shaanxi 712100, China \\ ${ }^{\mathrm{b}}$ Institute of Cellular and Molecular Biology, Xuzhou Normal University, Xuzhou, \\ Jiangsu 221116, China
}

(Received 15 December 2005; accepted 18 April 2006)

\begin{abstract}
Two Y chromosome specific microsatellites UMN2404 and UMN0103 were genotyped and assessed for polymorphisms in a total of 423 unrelated males from 25 indigenous Chinese cattle breeds. Consistently, both microsatellites displayed specific indicine and taurine alleles in each bull examined. The indicine and taurine alleles were detected in 248 males (58.6\%), and 175 males (41.4\%), respectively, although these frequencies varied amongst different breeds examined. The indicine alleles dominated in the southern group (92.4\%), while the taurine alleles dominated in the northern group (95.5\%). Hainan Island was possibly the site for the origin of Chinese zebu, and Tibetan cattle were probably independently domesticated from another strain of Bos primigenius. The geographical distribution of these frequencies reveals a pattern of male indicine introgression and a hybrid zone of indicine and taurine cattle in China. The declining south-to-north and east-to-west gradient of male indicine introgression in China could be explained by historical data, geographical segregation and temperature and weather conditions.
\end{abstract}

Chinese cattle / taurine / indicine / genetic introgression / Y chromosome

\section{INTRODUCTION}

China is rich in genetic resources of cattle breeds, with 28 indigenous and other cattle breeds [15]. These cattle breeds have been divided into three major groups on the basis of their geographical distribution, morphological characteristics and sex chromosome polymorphisms: the northern group in northern China, the central area group in the middle and lower areas of the Yellow River and the Huaihe River, and the southern group in southern China $[2,15]$.

Attempts have been made to trace the origins and phylogenetic relationships of indigenous Chinese cattle through the analysis of morphology, protein loci

*Corresponding author: chenhong1212@263.net 
and mtDNA RFLP. The common view is that Chinese cattle breeds could be classified into four origins: Bos taurus, Bos indicus, Bos javanicus, Bos gaurus, and even Bos grunniens [5,12,21]. Nevertheless, some western scientists hold the view that Chinese native cattle breeds are admixtures of Bos taurus and Bos indicus $[13,14]$. The study of sex chromosome morphology and mtDNA D-loop region sequence data have indicated that the taurine (Bos taurus) had a higher genetic influence on the development of the northern group of breeds than the indicine (Bos indicus), while the indicine had a higher genetic influence on the development of the southern group of breeds. Both the taurine and indicine contributed to the formation of the central area group of cattle breeds $[2,8,9]$.

The Y-specific region constituting about $95 \%$ of the Y chromosome is immune to recombination and inherited "en bloc" as a haplotype, which ensures that original combinations of mutational events along male lineages are preserved as single linked unambiguous haplotypes. Y chromosomespecific microsatellites of bovines are effectively haploid and paternally inherited $[7,10,11]$. Two Y-specific microsatellites $U M N 2404$ and $U M N 0103$ have been reported to be polymorphic in some domestic cattle breeds, which were also used for the construction of a first generation radiation hybrid map for the bovine Y chromosome [10,11]. The purposes of this work were to genotype the two Y-specific microsatellites and assess for their polymorphisms in indigenous Chinese cattle breeds.

\section{MATERIALS AND METHODS}

A total of 423 unrelated males from 25 indigenous breeds representing the three major groups of Chinese cattle (northern group, central area group, southern group) were sampled. These sampled bulls were from a fair geographical distribution, as shown in Figure 1 and Table I. As a control, microsatellite sizes of taurine (Angus, introduced from England) and indicine (Brahman, from USA) were established by molecular methods. In addition a small number of females (1-3) from each breed were screened to ensure Y-chromosome specificity of the markers.

Genomic DNA was isolated from muscle tissue and whole blood using the normal method of phenol-chloroform extraction [16]. The primers of UMN2404 (forward primer 5'-GGTACAATTGAAAATATG-3', reverse primer 5'-TGTACCTACACTGATATGTT-3') and UMN0103 (forward primer 5'-ACACAGAGTATTCACCTGAG-3', reverse primer 5'-ATTTACC TGGGTCAAAGCAC-3') were developed by Liu et al. [10]. PCR was carried 


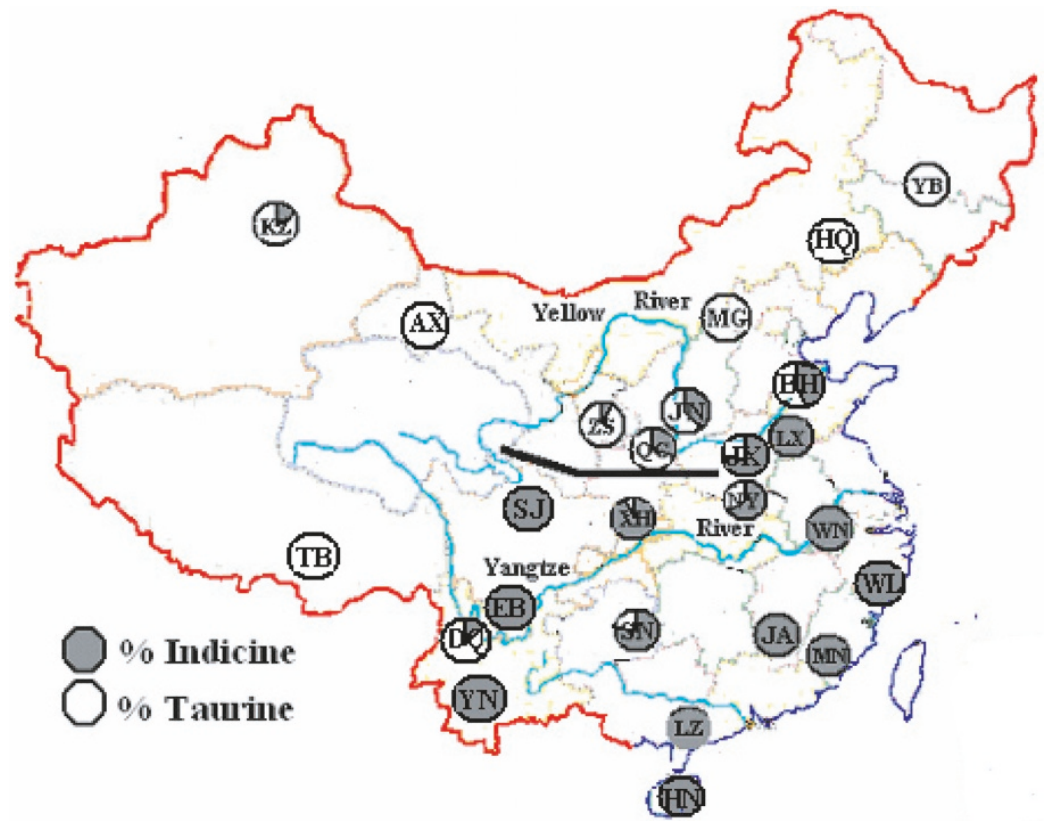

Figure 1. Frequency of taurine and indicine Y chromosome alleles in Chinese cattle breeds. In black, indicine Y-chromosome, and in white, taurine. KZ, Kazakh; AX, Anxi; ZS, Zaosheng; MG, Mongolia; HQ, Horqing; YB, Yanbian; QC, Qinchuan; JN, Jinnan; BH, Bohai Black; JX, Jiaxian Red; LX, Luxi; SJ, Sanjiang; XH, Xuanhan; NY, Nanyang; WN, Wannan; TB, Tibetan; EB, Ebian; SN, Sinan; JA, Ji' an; WL, Wenling hump; DQ, Diqing; MN, Minnan; YN, Yunnan hump; LZ, Leizhou; HN, Hainan. The bold line indicates the Qinling Mountains.

out on a PTC-200 thermocycler (MJ Research Inc.) in $15 \mu \mathrm{L}$ reaction volume containing $20 \mathrm{ng}$ of DNA, $0.4 \mu \mathrm{M}$ of each primer, $50 \mu \mathrm{M}$ of each dNTP (Tiangen Biotech Co., Ltd, Beijing, China), 0.6 U of Taq DNA polymerase (SinoAmerican Biotechnology Co., Luoyang, Henan province China), $1 \times \mathrm{PCR}$ buffer (10 mM Tris- $\mathrm{HCl}\left[\mathrm{pH} 9.0\right.$ at $\left.25^{\circ} \mathrm{C}\right] ; 1.5 \mathrm{mM} \mathrm{MgCl}_{2} ; 50 \mathrm{mM} \mathrm{KCl} ; 0.1 \%$ Triton X-100). The amplification cycle of $U M N 2404$ included denaturation at $95{ }^{\circ} \mathrm{C}$ for $5 \mathrm{~min}$, then followed by 36 cycles at $94{ }^{\circ} \mathrm{C}$ for $30 \mathrm{~s}, 54{ }^{\circ} \mathrm{C}$ for $30 \mathrm{~s}$, $72{ }^{\circ} \mathrm{C}$ for $30 \mathrm{~s}$, and a final extension step at $72{ }^{\circ} \mathrm{C}$ for $5 \mathrm{~min}$. TouchDown PCR was carried out to amplify UMN0103 under the following conditions: $94{ }^{\circ} \mathrm{C}$ for $3 \mathrm{~min}$, followed by 40 cycles of $94{ }^{\circ} \mathrm{C}$ for $30 \mathrm{~s}, 65-55^{\circ} \mathrm{C}$ for $30 \mathrm{~s}$ and $72{ }^{\circ} \mathrm{C}$ for $30 \mathrm{~s}$. Annealing temperatures were decreased from 65 to $55^{\circ} \mathrm{C}$ with the decrements of $0.5^{\circ} \mathrm{C}$ successively for each of the first 21 cycles.

The specific taurine or indicine alleles were distinguished by polyacrylamide gel $(8 \%)$ electrophoresis, visualized using silver stain and analyzed 
Table I. Number and frequency (\%) of indicine and taurine alleles in Chinese cattle breeds and cattle groups.

\begin{tabular}{|c|c|c|c|c|c|c|}
\hline \multirow[t]{2}{*}{ Groups } & \multirow[t]{2}{*}{ Breeds } & \multirow{2}{*}{$\begin{array}{l}\text { Geographical } \\
\text { distribution }\end{array}$} & \multicolumn{2}{|c|}{ Number of Y alleles } & \multicolumn{2}{|c|}{ Frequency of Y alleles } \\
\hline & & & Indicine & Taurine & Indicine & Taurine \\
\hline \multirow[t]{8}{*}{ Northern } & Anxi (AX) & $\begin{array}{l}\text { Northwestern region of } \\
\text { the Gansu province }\end{array}$ & 0 & 15 & 0 & 100 \\
\hline & Mongolia (MG) & $\begin{array}{l}\text { Inner Mongolia, Shanxi } \\
\text { and the Hebei province, } \\
\text { and Northeast China }\end{array}$ & 0 & 7 & 0 & 100 \\
\hline & Horqing (HQ) & Inner Mongolia & 0 & 13 & 0 & 100 \\
\hline & Yanbian(YB) & $\begin{array}{l}\text { Jiling, Liaoning and the } \\
\text { Heilongjiang province } \\
\text { and inner Mongolia }\end{array}$ & 0 & 22 & 0 & 100 \\
\hline & Tibetan (TB) & Southern region of Tibet & 0 & 8 & 0 & 100 \\
\hline & Zaosheng (ZS) & $\begin{array}{l}\text { Northeast region of } \\
\text { converging regions of } \\
\text { Ningxia and the Gansu } \\
\text { province }\end{array}$ & 2 & 27 & 6.9 & 93.1 \\
\hline & Kazakh (KZ) & $\begin{array}{l}\text { Northern region of the } \\
\text { Xinjiang province }\end{array}$ & 3 & 15 & 16.7 & 83.3 \\
\hline & $\begin{array}{l}\text { Total numbers } \\
\text { and frequencies }\end{array}$ & & 5 & 107 & 4.5 & 95.5 \\
\hline \multirow[t]{7}{*}{$\begin{array}{l}\text { Central } \\
\text { Area }\end{array}$} & Qinchuan (QC) & $\begin{array}{l}\text { Guanzhong reagion of } \\
\text { the Shaanxi province }\end{array}$ & 10 & 21 & 32.3 & 67.7 \\
\hline & Jinnan (JN) & $\begin{array}{l}\text { Southern region of the } \\
\text { Shanxi province }\end{array}$ & 5 & 8 & 38.5 & 61.5 \\
\hline & Bohai & Northwest region of the & 8 & 11 & 42.1 & 57.9 \\
\hline & $\begin{array}{l}\text { Black (BH) } \\
\text { Nanyang (NY) }\end{array}$ & $\begin{array}{l}\text { Shandong province } \\
\text { Southern region of the } \\
\text { Henan province }\end{array}$ & 18 & 10 & 64.3 & 35.7 \\
\hline & Jiaxian Red (JX) & $\begin{array}{l}\text { Jiaxian and Baofeng } \\
\text { couties of the Henan } \\
\text { province }\end{array}$ & 12 & 4 & 75 & 25 \\
\hline & $\operatorname{Luxi}(\mathrm{LX})$ & $\begin{array}{l}\text { Southwestern region of } \\
\text { the Shandong province }\end{array}$ & 19 & 0 & 100 & 0 \\
\hline & $\begin{array}{l}\text { Total numbers } \\
\text { and frequencies }\end{array}$ & & 72 & 54 & 57.1 & 42.9 \\
\hline \multirow[t]{13}{*}{ Southern } & Diqing (DQ) & $\begin{array}{l}\text { Diqing region of the } \\
\text { Yunnan province }\end{array}$ & 2 & 9 & 18.2 & 81.8 \\
\hline & $\operatorname{Sinan}(\mathrm{SN})$ & $\begin{array}{l}\text { Northeast region of the } \\
\text { Guizhou province }\end{array}$ & 13 & 4 & 76.5 & 23.5 \\
\hline & Xuanhan (XH) & $\begin{array}{l}\text { Converging regions of } \\
\text { Shaanxi, Sichuan and the } \\
\text { Hubei province }\end{array}$ & 12 & 1 & 92.3 & 7.7 \\
\hline & Sanjiang (SJ) & $\begin{array}{l}\text { Northern region of the } \\
\text { Sichuan province }\end{array}$ & 8 & 0 & 100 & 0 \\
\hline & Ebian (EB) & $\begin{array}{l}\text { Liangshan region of the } \\
\text { Sichuan province }\end{array}$ & 14 & 0 & 100 & 0 \\
\hline & Wannan (WN) & $\begin{array}{l}\text { Regions in the Anhui } \\
\text { province along the } \\
\text { Yangtze River }\end{array}$ & 32 & 0 & 100 & 0 \\
\hline & $\begin{array}{l}\text { Wenling } \\
\text { hump (WL) }\end{array}$ & $\begin{array}{l}\text { Wenling city of the } \\
\text { Zhejiang province }\end{array}$ & 11 & 0 & 100 & 0 \\
\hline & $\mathrm{Ji}$ ' an (JA) & $\begin{array}{l}\text { Southern region of the } \\
\text { Jiangxi province }\end{array}$ & 9 & 0 & 100 & 0 \\
\hline & Minnan (MN) & $\begin{array}{l}\text { Sorthern region of the } \\
\text { Fujian province }\end{array}$ & 22 & 0 & 100 & 0 \\
\hline & $\begin{array}{l}\text { Yunnan } \\
\text { hump (YN) }\end{array}$ & $\begin{array}{l}\text { Southern region of the } \\
\text { Yunnan province }\end{array}$ & 10 & 0 & 100 & 0 \\
\hline & Leizhou (LZ) & $\begin{array}{l}\text { Converging regions of } \\
\text { Guangdong and the } \\
\text { Heinan province }\end{array}$ & 21 & 0 & 100 & 0 \\
\hline & Hainan (HN) & $\begin{array}{l}\text { Northern region of the } \\
\text { Heinan province }\end{array}$ & 17 & 0 & 100 & 0 \\
\hline & $\begin{array}{l}\text { Total numbers } \\
\text { and frequencies }\end{array}$ & & 171 & 14 & 92.4 & 7.6 \\
\hline $\begin{array}{l}\text { All } \\
\text { breeds }\end{array}$ & & & 248 & 175 & 58.6 & 41.4 \\
\hline
\end{tabular}


by employing the Discovery Series Quantity One Software Version 4.3.1 (Bio-Rad Laboratoris Inc.). The frequency of the alleles was determined by direct counting.

\section{RESULTS}

The microsatellites UMN2404 and UMN0103 were assessed for polymorphisms in 17 unrelated bulls by Liu et al. [10]. UMN2404 displayed a typical ladder-like band ranging from 85 bp to 112 bp and UMN0103 presented fewer bands ranging from $124 \mathrm{bp}$ to $136 \mathrm{bp}$ [10]. The Chinese cattle are divided into two major morphological groups, the humped indicine and humpless taurine types. Accordingly, the UMN2404 microsatellite showed specific taurine (Angus) (104 bp, $91 \mathrm{bp}$ ) and indicine (Brahman) (120 bp, $110 \mathrm{bp}, 85 \mathrm{bp}$ ) alleles in these indigenous breeds. Interestingly, UMN0103 also displayed specific taurine (155 bp, $140 \mathrm{bp}$ ) and indicine (136 bp, $125 \mathrm{bp}$ ) alleles consistent with UMN2404 in each bull examined. The bulls of five breeds (Anxi, Tibetan, Mongolia, Horqing and Yanbian cattle) were totally genotyped as taurines, while all the individuals in ten breeds (Luxi, Sanjiang, Ebian, Wannan, Wenling hump, Ji'an, Minnan, Yunnan hump, Leizhou and Hainan cattle) were genotyped as indicines. The frequencies of the taurine and indicine specific alleles in the indigenous Chinese cattle breeds are shown in Figure 1 and Table I.

Amongst the 25 indigenous Chinese cattle breeds (423 males), the indicine alleles were higher, comprising $58.6 \%$ of the alleles observed (Tab. I). Seven breeds of the northern cattle group studied were from ten provinces. The frequency of taurine alleles in the northern group was predominant, comprising $95.5 \%$ of the animals examined. Only two indicine bulls were observed in 29 Zaosheng cattle (ZS) and three in 18 Kazakh cattle (KZ). Twelve breeds of the southern group sampled from 11 provinces were examined in this study. In over a total of 185 bulls from the southern group, the taurine alleles were detected in one Xuanhan (XH) male, 9 Diqing males (DQ) and four Sinan bulls $(\mathrm{SN})(7.6 \%)$, while the indicine ones were observed in 171 sires of the 12 breeds from the southern group $(92.4 \%)$. The frequency and geographical distribution of taurine and indicine alleles among cattle breeds from the central area group were also not homogenous. The taurine alleles were detected in $67.7 \%$ of the Qinchuan bulls (QC) examined, 61.5\% of the Jinnan males (JN), $57.9 \%$ of Bohai Black cattle (BH), 35.5\% of the Nanyang sires (NY) and $25 \%$ of the Jiaxian Red animals (JX), but none were observed in the animals of the Luxi breeds (LX). 
Previous cytogenetic research on the indigenous Chinese cattle breeds showed that the male indicine Y chromosome was present in $100 \%$ of Hainan (HN), Wenling hump (WL), Ebian (EB), NY and LX males; 75\% of JX cattle; $25 \%$ of QC bulls; and in $22.2 \%$ of JN breeds, but it was absent in Mongolia (MG) and Tibetan cattle (TB) $[2,3,6,19,20]$. The analysis of these data and our results indicate that the frequency of the indicine $\mathrm{Y}$ chromosome among Chinese cattle breeds ranged from 0 to $100 \%$. As shown in Figure 1, the geographical distribution of these two types of alleles reveals a declining southto-north and east-to-west gradient of male indicine introgression in China.

\section{DISCUSSION}

The origin, domestication and migration of indigenous Chinese cattle are much more complicated due to their complex and extensive geographical distribution. In this work, we genotyped the Y chromosome microsatellites $U M N 2404$ and $U M N 0103$, which consistently showed specific indicine and taurine alleles in 25 Chinese cattle breeds. The assessment of UMN2404 and $U M N 0103$ for their polymorphisms revealed the geographical distribution and frequency of male taurine and indicine in Chinese cattle. The declining south-to-north and east-to-west gradient of male indicine introgression in China could be explained by historical data, geographical segregation and temperature weather conditions.

Among the 423 Chinese bulls analyzed, 248 were genotyped as indicine while the remaining belonged to the taurine type. The frequencies of the taurine and indicine alleles differed in the regional matrilineal pool of cattle in China. For instance, the indicine alleles dominated in the southern group $(92.4 \% ; 171 / 185)$ and still took a higher percentage in the central area group $(57.1 \% ; 72 / 126)$, while the taurine alleles dominated in the northern group $(95.5 \%$; 107/112) (Tab. I). This pattern was consistent with the findings based on the analysis of mtDNA RFLP and mtDNA D-loop sequence diversity, suggesting that cattle from South China received more genetic contribution from the indicine $[8,21]$.

The earliest domestic cattle in North China were the progenies of the Longhorn of Bos taurus from Western Europe, which were distinguished from bachryseros and primigenius of Bos taurus, and appeared between 3766 and 3122 years B.P. (before present) with the introgression of Mongolian into the huge and extensive area to the north of the Great Wall $[4,5,13]$. These taurine cattle gradually adapted to the local environmental conditions and expanded 
southward but the Qinling Mountains and temperature and weather constituted the natural barriers to their expansion. Therefore, the highest percentages of taurine were examined in the cattle from the northern group, with 100\%, 100\%, $100 \%, 100 \%, 93.1 \%$ and $83.3 \%$ of taurine alleles in AX, MG, HQ, YB, ZS and $\mathrm{KZ}$, respectively. Meanwhile, the lower percentages of indicine introgression in $\mathrm{KZ}$ and $\mathrm{ZS}$ resulted from the introduction of zebu from North Africa and the hybridization between African zebu and indigenous taurine through the Silk Road of ancient China $[4,5]$.

Interestingly, the eight Tibetan bulls examined were totally genotyped as taurine, which indicated Tibet was not only a habitat of yak, but also a habitat of taurine in China. This result was consistent with the research based on cytogenetic analysis by Chen et al. [6], who suggested that Tibetan cattle were probably the progenies of another strain of Bos primigenius. Similarly, the research of Tu and Zhang [18] indicated that Tibetan cattle are one of the strains of Bos taurus independently domesticated from local wild cattle. Based on the study of morphological features, blood protein polymorphisms and cytogenetic analysis, Qiu et al. [15] proposed that Tibetan cattle should be included in the northern cattle group, and in this work we analyzed Tibetan cattle in the northern cattle group.

The humped zebu inhabited in the vast and huge areas of the Yangtze River and the Zhujiang River as early as 5500 years B.P. and they might originate from the Bibos genus, such as zebu, Bos bateng and even Bos gaurus, which were also the progenitors of the zebu from Southeastern Asia [4, 5, 13, 15]. In this sense, the predominantly higher percentages of indicine alleles detected in the southern group agreed with the massive distribution of Chinese zebu in south China. Here the Qinling Mountains and temperature and weather also constituted the main natural barriers to the northward expansion of Chinese zebu. The results of research on six types of blood protein $(\mathrm{Hb}, \mathrm{Alb}, \mathrm{Pa}, \mathrm{Tf}$, Ptf and Akp) polymorphisms of 27 thousand cattle distributed in the northern and southern flank regions along the Qinling Moutains revealed that genemigration had occurred among QC, Xizhen cattle (XZ) and XH [1]. Thus, the small amount of taurine $\mathrm{Y}$ chromosome transmission into $\mathrm{XH}$ was due to the gene-exchanging between QC and XH. Unexpectedly, much higher taurine alleles $(81.8 \%)$ were observed in Diqing cattle. This could be explained by the similarity of the habitat of Diqing cattle to that of Tibetan cattle. The Diqing region where Diqing cattle inhabit is located is in the northwest region of the Yunnan province and is a southern extension of the Tibet-Qinghai plateau, which is on average 2800-3300 meters above sea level. Diqing cattle are humpless and show taurine-like morphological features, and have adapted 
to the cold weather and high altitude. Therefore, this unique habitat also constituted a natural barrier to the introgression of indicine into Diqing cattle. The existence of taurine alleles in SN was due to some individuals of SN originating from hybridization between Bos taurus and Bos indicus [17,21].

Chen et al. [5] suggested that the indicine cattle from the eastern part of the central area have characteristics resembling those of zebu from Southeast Asia by coat color, body stature and blood protein polymorphisms, while those from the western and central parts have characteristics resembling those of the zebu from Africa and West Asia. In our study both the taurine and indicine alleles were observed in the cattle from the central area group, while the percentage of indicine was higher, comprising $57.1 \%$ of the individuals studied. Furthermore, a declining east-to-west gradient of male indicine introgression was evident, with $100 \%, 75 \%, 64.3 \%, 38.5 \%$ and $32.3 \%$ of indicine alleles in LX, JX, NY, QC and JN, respectively. The genetic influence of indicine to LX, JX and NY was significantly greater than that to QC, JN and BH; conversely, the influence of taurine to $\mathrm{QC}, \mathrm{JN}$ and $\mathrm{BH}$ was greater than that to $\mathrm{LX}$, JX and NY. This result was consistent with the gradient described by Chen et al. [2] and Lai et al. [8].

Moreover, a hybrid zone in the central area of China between the two types of alleles was also revealed in this work. Our results indicate that the influence of indicine from South China, detouring the Qinling Moutains and dispersing along a south-to-north direction, has reached the Guanzhong region of the Shaanxi province, the Jinnan region of the Shanxi province and the northwest area of the Shandong province, with the indicine alleles present in QC, JN and $\mathrm{BH}$, respectively. It is possible that the gradual adaptation of indicine to the relatively cold and dry weather of northern China will facilitate their northward and westward dispersion.

Finally, the declining south-to-north and east-to-west gradient of the male indicine introgression pattern in China indicated that the Hainan Island to the southern most continent of China was possibly the site for the origin of Chinese zebu in paternal lineage. Our result is supported by the research on the gene frequency of $\mathrm{Tf}^{\mathrm{F}}$ in Hainan cattle $[4,5]$.

This work, for the first time, establishes a pattern of male indicine introgression in China using two polymorphic Y chromosome specific markers. The extent of male indicine influence on indigenous Chinese cattle clearly emerged from our results (Fig. 1). It appears that relative geographical segregation, environmental and temperature and weather conditions have prevented the spread of the indicine $\mathrm{Y}$ alleles throughout China. 


\section{ACKNOWLEDGEMENTS}

We thank Dr. Zhiqing Zhang for providing blood and muscle tissue samples of Qinchuan, Nanyang and Luxi cattle. We are also thankful to Prof. Lihong $\mathrm{Su}$, Ms. Shenrong $\mathrm{Hu}$, Dr. Chunlei Zhang and other colleagues working in the College of Animal Science and Technology, Northwest A\&F University, for their support of the experiment and suggestions to this paper. Still we are grateful to Prof. Paul Bach (Xi' an Foreign Language University, China) and Dr. Zhiying Zhang (Gemin X Biotechnologies Inc., Quebec, Canada) for their help in editing the language and comments on the manuscript. This research was supported by grants from the National Natural Science Foundation of China (No. 30471238), Project Supporting of Excellent Researchers of Northwest A\&F University (No. 01140101) and Creativity Education Project of Graduate Students of Northwest A\&F University (No. 05YCH018).

\section{REFERENCES}

[1] Chang H., Geng S.M., Wu B., Chen Y.C., Reports on Population Genetic Research of Cattle Breeds at Two Flank Regions of Qinling Moutains, in: Chang H., Genetic Resource Research on Livestock in China, Shaanxi People's Education Publisher, Shaanxi, China, 1998, pp. 159-166 (in Chinese).

[2] Chen H., Qiu H., Zhan T.S., Jia J.X., Studies on sex chromosome polymorphism of four local cattle breeds in China, Hereditas (Beijing) 15 (1993) 14-17 (in Chinese with English abstract).

[3] Chen L., Yu R.L., Chen Y.C., The preliminary observation of Y chromosome of Heinan yellow cattle, Chin. J. Anim. Sci. 5 (1988) 29 (in Chinese with English abstract).

[4] Chen Y.C., Cao H.H., Diversity of Chinese yellow cattle breeds and their conservation, Chinese Biodiversity 9 (2001) 275-283 (in Chinese with English abstract).

[5] Chen Y.C., Wang Y.Y., Cao H.H., Zhang Y., Characteristics of Chinese Yellow Cattle Ecospecies and Their Course of Utilization. Agricultural Publishing House, Beijing, China, 1990 (in Chinese).

[6] Chen Z.H., Zhong J.C., Deng X.Y., La N., A study on Y chromosome of Tibetan yellow cattle, J. Yellow Cattle Sci. 21 (1995) 1-2 (in Chinese with English abstract).

[7] Edwards C.J., Gaillard C., Bradley D.G., MacHugh D.E., Y-specific microsatellite polymorphisms in a range of bovid species, Anim. Genet. 31 (2000) 127-130.

[8] Lai S.J., Liu Y.P., Liu Y.X., Li X.W., Yao Y.G., Genetic diversity and origin of Chinese cattle revealed by mtDNA D-loop sequence variation, Mol. Phylogenet. Evol. 38 (2006) 146-154. 
[9] Lei C.Z., Chen H., Yang G.S., Song L.S., Lei X.Q., Sun W.B., Li R.B., Liu X.L., Study on mitochondrial DNA genetic diversity of some cattle breeds in China, Acta Genet. Sin. 31 (2004) 57-62 (in Chinese with English abstract).

[10] Liu W.S., Paola M., Beattie C.W., Alexander L.J., Ponce de Len F.A., A radiation hybrid map for the bovine Y chromosome, Mamm. Genome 13 (2002) 320-326.

[11] Liu W.S, Beattie C.W., Ponce de Len F.A., Bovine Y chromosome microsatellite polymorphisms, Cytogenet. Genome Res. 102 (2003) 53-58.

[12] Nei L., Yu Y., Zhang X.Q., Yang G.F., Wen J.K., Zhang Y.P., Genetic diversity of cattle in South China as revealed by blood protein electrophoresis, Biochem. Genet. 37 (1999) 257-265.

[13] Payne W.J.A., Tropical Cattle: Origins, Breeds and Breeding Policy, Blackwell Science, Oxford, 1995.

[14] Phillips W., World distribution of the major types of cattle, J. Heredity 86 (1961) 248-249.

[15] Qiu H., Qing Z.R., Chen Y.C., Wang A.D., Bovine Breeds in China, Shanghai Scientific and Technical Publishers, Shanghai, China, 1988.

[16] Sambrook J., Fritsch E.F., Maniatis T., Molecular Cloning: A Laboratory Manual, 2nd edn., Cold Spring Harbor Laboratory Press, Cold Spring Harbor, NY, 1989.

[17] Shan X.N., Chen Y.F., Luo L.H., Cao X.M., Song J.Z., Zeng Y.Z., Comparative studies on the Chromosomes of five species of cattle of Genus Bos in China, Zool. Res. 1 (1980) 75-81 (in Chinese with English abstract).

[18] Tu Z.C., Zhang Y.P., Genetic diversity in native Chinese cattle, Chinese Biodiversity 5 (1997) 90-94 (in Chinese with English abstract).

[19] Yu R.L., Chen L., Chen Y.C., The study on chromosome of Ebian cattle, J. Yellow Cattle Sci. 15 (1989) 10-12 (in Chinese with English abstract).

[20] Yu R.L., Xin C.Y., Li S.H., Zhen J.Z., Qi K.J., Lin L.Z., The 2/27 Robertsonian translocation in Wenling hump cattle, Hereditas (Beijing) 13 (1991) 17-18 (in Chinese with English abstract).

[21] Yu Y., Nie L., He Z.Q., Wen J.K., Jian C.S., Zhang Y.P., Mitochondrial DNA variation in cattle of South China: origin and introgression, Anim. Genet. 30 (1999) 245-250. 